Research Article

\title{
Stability Analysis of Surrounding Rock and Treatment Structures in Superlarge Karst Cave of Naqiu Tunnel
}

\author{
HuaWei Chen (D) $^{1}$ and Ce Sha ${ }^{2}$ \\ ${ }^{1}$ Hunan Provincial Communications Planning Survey and Design Institute, Changsha, China \\ ${ }^{2}$ Zhejiang Institute of Security Technology, Wenzhou, Zhejiang 325016, China
}

Correspondence should be addressed to HuaWei Chen; hwchenhnjt@sina.com

Received 16 April 2018; Accepted 13 June 2018; Published 26 July 2018

Academic Editor: Giovanni Garcea

Copyright (c) 2018 HuaWei Chen and Ce Sha. This is an open access article distributed under the Creative Commons Attribution License, which permits unrestricted use, distribution, and reproduction in any medium, provided the original work is properly cited.

\begin{abstract}
This study relied on the treatment and construction process of the corridor hall-type large karst cave of Naqiu Tunnel, and field tests and numerical simulation were carried out to investigate the stability of surrounding rock and treatment structures during the tunnel excavation process. From the results of different excavation footages, both the displacement characteristics between the backfill pile-bearing platform-retaining wall compound treatment structures with surrounding rock and the stress changes of the initial support were analyzed. Combining with the field tests and simulation results, it can be obtained that the compound treatment structure under the bias voltage has unequal leftward displacement and settlement. When the distance to excavation surface gets closer, the bias effect will become greater on the horizontal displacement than on the vertical displacement. Both the displacement and stress changes tend to be stable after the excavation is completed, which proves that the treatment structure of the foundation, bearing platform, retaining wall, and lining structure on the steep slope section is stable and effectively suppresses the effect of the surrounding rock bias voltage. All above conclusions can provide theoretical basis and construction reference for similar projects.
\end{abstract}

\section{Introduction}

With the continuous development of infrastructure and economic construction in Central China and Western China, the transportation infrastructure has been developing rapidly. In the construction of highways and railways in hilly areas, it is necessary to build tunnels $[1,2]$. It should be noted that karst disasters are frequent in the central and western regions, and the karst environment is various in different regions. The tunnel structure will be affected by both the natural geological form and artificial excavation, which will make the construction process more complicated and difficult $[3,4]$.

In recent years, research studies on the influence of the karst cave on tunnel engineering have been carried out. Mengjun et al. [5] used model tests and numerical simulations to study the influence of the diameter ratio of the karst cave and tunnel and the relationship between the spatial position of the karst cave and tunnel geometry on the displacement, stress, and stability of the surrounding rock. Based on the karst tunnel project of the high-speed railway segment, Yangchun and Xiaojun [6] used FLAC3D to simulate the excavation stability of the tunnel with horizontal karst caves. Yuanhai et al. [7] studied the effect of karst caves on the stability of the surrounding rock for the Dayaoshan Tunnel and compared the filling and grouting reinforcement schemes when tunneling through the karst caves. Based on the elastic-plastic theory, Xianju and Mengtao [8] analyzed the stability of the surrounding rock and support of the karst tunnel using finite element software. Peiguo and Huajun [9] analyzed the large deformation of the surrounding rock of tunnels through filled karst caves and introduced the mechanism of the initial arching foot to cause the overall deformation of the tunnel and proposed the main treatment measures. Shubin et al. [10] conducted a model test for the tunnel excavation near the pressure-bearing 
chamber and obtained the stress-strain characteristics of the key locations in the tunnel excavation process at a certain cavity size and internal pressure.

The above research is concentrated on medium and small karst tunnels. However, the tunnel engineering research for the superlarge corridor hall cave is not yet thorough. It takes into account the development of a large cavity invading the tunnel profile, backfill foundation in the steep slope geological section, complex treatment structure, and other special factors. The stability analysis of complex structures such as pile foundation on steep slope-retaining wall-primary support and surrounding rock is still a major problem to be studied. Therefore, the stability of wall rock and complex treatment structures during the excavation of extremely large karst tunnels is studied in depth in this paper through numerical simulation and field testing, taking the superlarge karst cave in the left line of Naqiu Tunnel as the engineering background. On the one hand, it verifies the rationality of the actual design and construction. On the other hand, it can provide guidance and theoretical basis for the treatment and excavation of similar karst tunnels.

\section{Engineering Background}

Naqiu Tunnel is located in Furong Town, Yongshun County, Xiangxi, Hunan Province. It is a one-way doubletrack tunnel with a total length of $2860 \mathrm{~m}$. The superlarge karst cave of the corridor hall type is located on the left line $\mathrm{K} 14+350-520$. The cave is $170 \mathrm{~m}$ long and is basically coincided with the direction of the tunnel. The location of the tunnel and cave is shown in Figure 1(a). The surrounding rock of the tunnel is composed of microweathered limestone. It is a medium-thick layered structure and belongs to Class III surrounding rock. Its destruction form is dominated by falling blocks. The karst cave is basically developed and formed, and there are local surrounding rock structures with poor stability. They belong to Grade IV surrounding rocks and may produce smallscale rockfalls. The original landform of the karst cave is shown in Figure 1(b).

According to the detailed geological survey report of the karst section, three schemes for cave treatment were put forward: bridge, line change, and backfill. From the aspects of reasonableness, safety, environmental protection, easy construction, and low cost, technical comparisons are considered. Specific backfilling geology and hydrological conditions are considered as well. Finally, the backfilling scheme is selected $[11,12]$, as shown in Figure 1(a).

For the special steep slope section of $\mathrm{K} 14+385-\mathrm{K} 14+415$, it is also the focus of this study. The average height difference of the cave is $30 \mathrm{~m}$, and the width is relatively large. The impact of steep slopes on the backfills in different backfill areas may produce large inhomogeneous deformation over time and reduce the stability of the backfilling foundation. In order to avoid the influence of vehicle load and structural load and bias load of surrounding rock after excavation, the backfill pile-retaining wall joint treatment scheme was uniquely adopted on the basis of the backfilling scheme. The implementation of this program can enhance the stability of the foundation. At the same time, it can form an integral structure with the surrounding rock and tunnel structure to better play the role of transmission load. The specific scheme is as follows.

As one of the supporting structures of the retaining wall and platform, the pile foundation adopts a $1.5 \mathrm{~m} \times 1.2 \mathrm{~m}$ rectangular pile structure and is arranged at the steep slope of the bottom of the cave. The total number is 9 , and the length of the pile is between 20 and $30 \mathrm{~m}$. The pile body is applied as a retaining wall, and the layered backfilling of the hole slag is carried out together. After reaching the elevation of the pile top, the pile body is poured to form a lower backfill-piled foundation roadbed; the vertical and horizontal frame girder structure is laid below the C30 concrete platform, and it is connected with the rock-socketed pile foundation to form an integral structure. The C30 reinforced concrete retaining wall structure is laid on the left side of the tunnel lining structure to support the bias effect caused by the cave roof and the irregular surrounding rock excavation. At the later stage of construction, the small cavity on the right side of the tunnel lining is filled with C20 concrete pumping, as shown in Figure 2.

\section{Calculation Model and Theoretical Parameters}

As shown in Figure 2(b), the cross section of K14+385 is selected as the study object in this paper. Based on the backfill pile-retaining wall and initial support joint treatment scheme, the section is modeled and calculated by FLAC3D. According to the actual situation, the depth of the tunnel is about $70 \mathrm{~m}$. The model uses the center of the tunnel as the origin of coordinates. The overall model is $120 \mathrm{~m}$ wide ( $x$-axis, horizontal), $30 \mathrm{~m}$ long ( $z$-axis, axial), and $146.27 \mathrm{~m}$ high ( $y$-axis, vertically radial). The left and right model boundaries are $50 \mathrm{~m}$ away from the tunnel center construction site. The computational model is divided into 94080 elements and 99231 nodes. The mesh is all hexahedral elements, as shown in Figure 3.

The Mohr-Coulomb constitutive model is used for the material of surrounding rock and the backfill, and the elastic model is used for the pile, bearing platform, and retaining wall $[13,14]$. According to the treatment scheme, geological survey, and rock mechanics test, the material mechanics parameters were determined, as shown in Table 1.

The boundary condition used in this model is the displacement constraint. The bottom and four sides of the model are fixed by the normal displacement. The top surface uses the free boundary. The gravity acceleration is $10 \mathrm{~N} / \mathrm{Kg}$, and the lateral pressure coefficient is $\lambda=0.6$. The excavation process was simulated according to the sequence of the initial ground stress field $\rightarrow$ displacement clearing $\rightarrow$ fullsection excavation $\rightarrow$ initial support $\rightarrow$ next excavation, which is carried out 10 times by using the "null" model in the FLAC3D, and the loop footage is $3 \mathrm{~m}$. The results are used to analyze the stress and strain of the pile foundation, platform, 


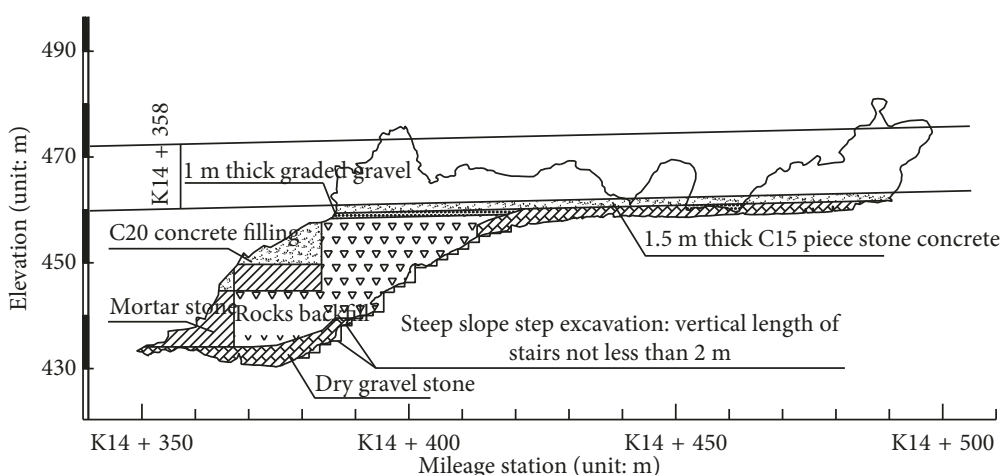

(a)

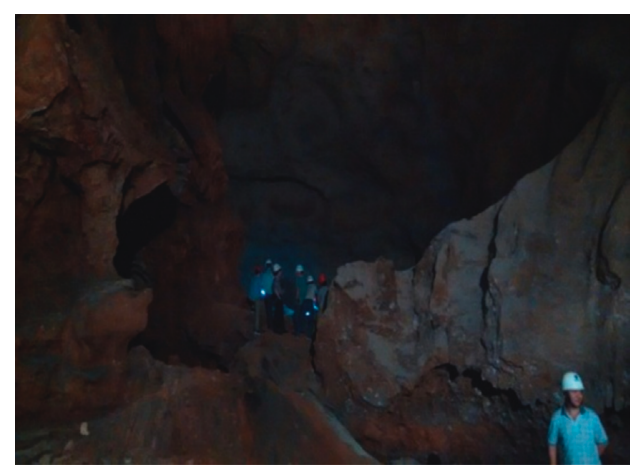

(b)

Figure 1: Tunnel and karst geomorphology: (a) the position of the tunnel and karst cave; (b) the original landform of the karst cave.

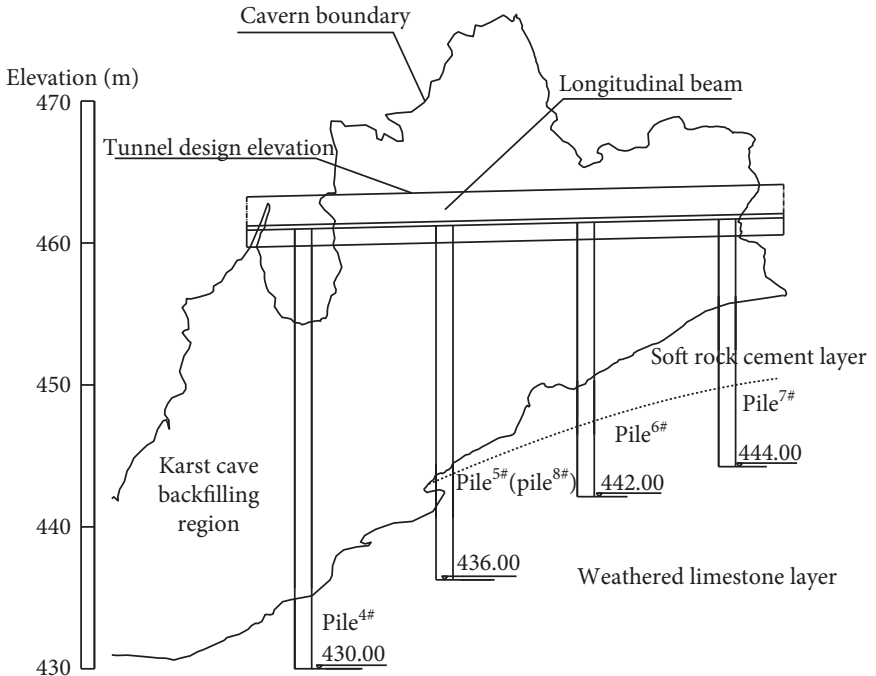

(a)

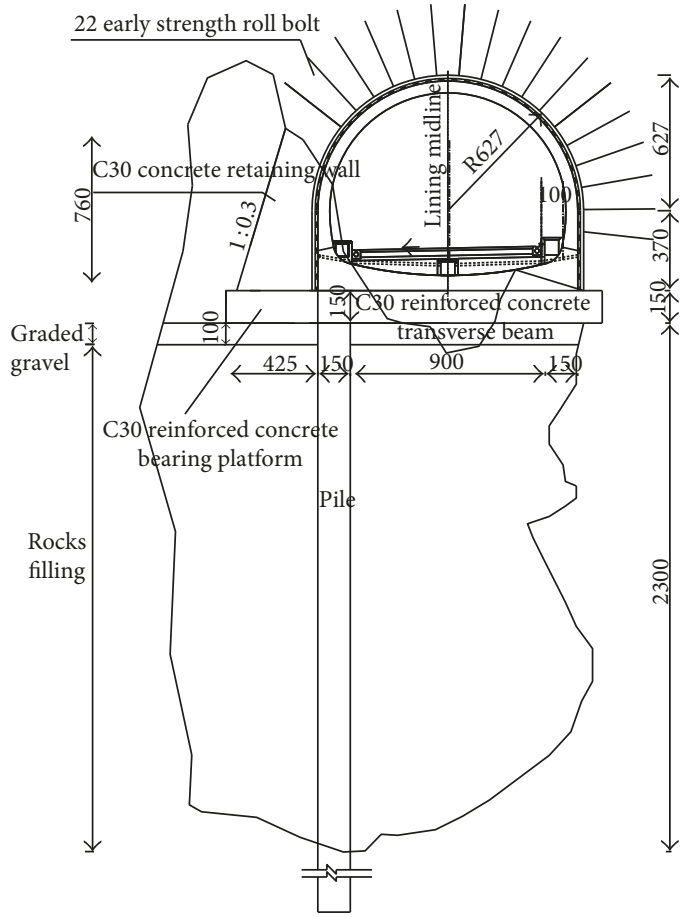

(b)

FIgURE 2: Treatment structure: (a) the longitudinal section of the treatment structure; (b) the cross section of K14 + 385.

retaining wall, surrounding rock, and initial lining structure under different processes.

\section{Calculation Results}

4.1. Displacement Analysis of the Pile Foundation. Figure 4 shows the position of the plane pile foundation. According to the simulation calculation, the displacement of the pile top under different excavation distances is shown in Figure 5. A negative value indicates horizontally to the left (or vertically downward), which is analyzed from the graph:

(1) The horizontal and vertical displacements of the three piles are all negative value; it proves that, after the excavation of the tunnel, there is a bias pressure from the surrounding rock, which makes the top of the pile arise leftward horizontal displacement and vertical settlement.

(2) The displacement on the left side of the pile top is slightly larger than that on the right side, the horizontal displacement value of no. 3 pile after the end of excavation reaches the maximum $1.79 \mathrm{~mm}$, the vertical displacement of the pile foundation is much smaller than the horizontal displacement, and the maximum vertical displacement difference between three pile foundations is $0.05 \mathrm{~mm}$. Therefore, the effect of excavation on the horizontal displacement of the pile foundation is much greater than that on the vertical displacement. 


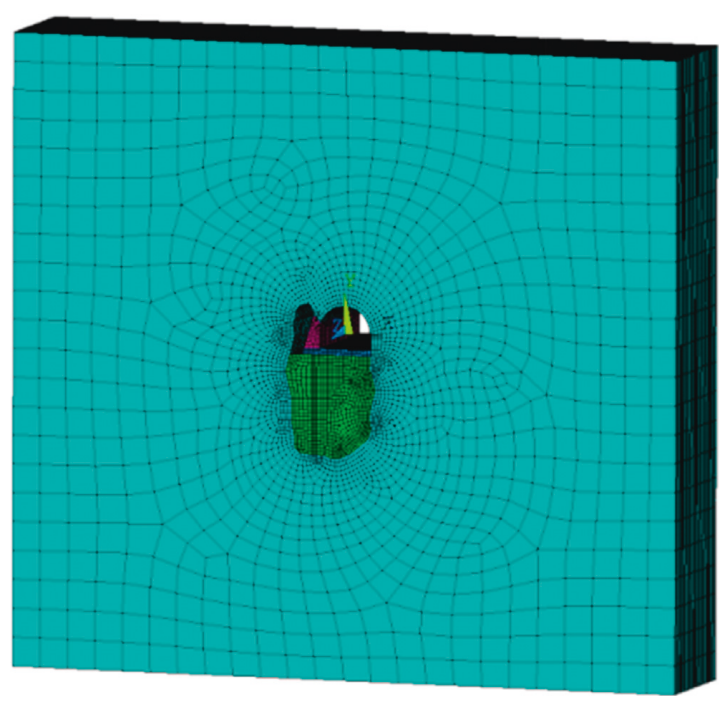

(a)

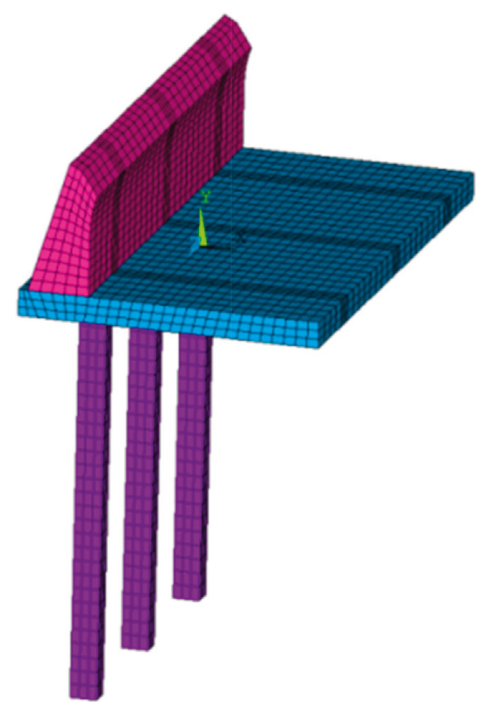

(b)

Figure 3: Numerical analysis model.

TABLE 1: Mechanical parameters of surrounding rock and artificial structure material.

\begin{tabular}{lccccccc}
\hline Material type & $\begin{array}{c}\text { Elastic modulus } \\
E(\mathrm{GPa})\end{array}$ & $\begin{array}{c}\text { Poisson's } \\
\text { ratio } \nu\end{array}$ & $\begin{array}{c}\text { Density } \rho \\
\left(\mathrm{kg} / \mathrm{m}^{3}\right)\end{array}$ & $\begin{array}{c}\text { Friction } \\
\text { angle } \varphi\left(^{\circ}\right)\end{array}$ & $\begin{array}{c}\text { Cohesive force } \\
\mathrm{C}(\mathrm{MPa})\end{array}$ & $\begin{array}{c}\text { Tensile/compressive } \\
\text { strength } \sigma(\mathrm{MPa})\end{array}$ & $\begin{array}{c}\text { Constitutive } \\
\text { model }\end{array}$ \\
\hline $\begin{array}{l}\text { Surrounding } \\
\text { rock }\end{array}$ & 5.0 & 0.3 & 2300 & 40 & 1.5 & 2.5 (tensile) & M-C \\
$\begin{array}{l}\text { Initial } \\
\text { support }\end{array}$ & 25.5 & 0.27 & 2350 & - & - & 2.4 (compressive) & Elastic \\
$\begin{array}{l}\text { Retaining } \\
\text { wall }\end{array}$ & 29.5 & 0.2 & 2450 & - & - & 20.1 (compressive) \\
$\begin{array}{l}\text { Bearing } \\
\text { platform }\end{array}$ & 29.5 & 0.2 & 2450 & - & - & 20.1 (compressive) & Elastic \\
$\begin{array}{l}\text { Pile } \\
\text { Backfill }\end{array}$ & 29.5 & 0.2 & 2450 & - & - & 20.1 (compressive) & Elastic \\
\hline
\end{tabular}

(3) As the excavation progresses, the horizontal displacement of the pile foundation near the excavation face is larger. As shown in Figure 5(a), the horizontal displacement of no. 1 pile increased with construction progresses firstly. As the excavation proceeds, the leftward displacement of nos. 2 and 3 piles starts to increase, and when the excavation of the face is completed, the horizontal displacement of the pile top reaches its maximum. As shown in Figure 5(b), the vertical displacement of the three piles increases quickly in early construction and gradually begins to reduce after the excavation of $9 \mathrm{~m}$, tending to the fixed value of $0.13 \mathrm{~mm}$ after the end of the excavation. The influence scope of overall excavation on the pile foundation is 9 10 $\mathrm{m}$ (Figure 6).

4.2. Displacement Analysis of the Bearing Platform. Figure 7 shows the layout of the monitoring point of the bearing platform, where nos. 7 and 9-10 feature points are located below the retaining wall. According to the simulation results, the displacement of the monitoring point of the

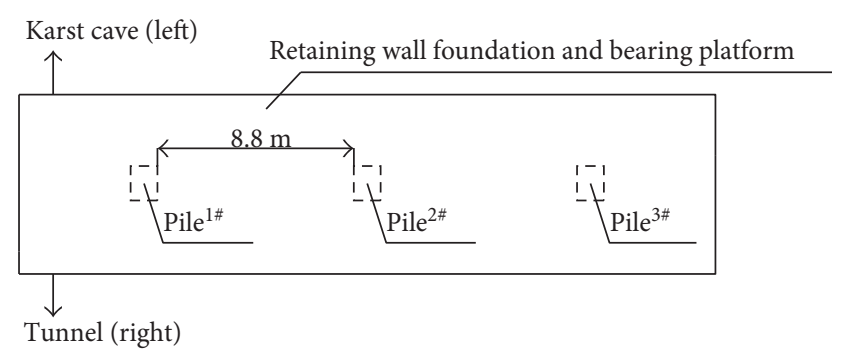

Figure 4: Position of the pile foundation.

bearing platform is shown in Figure 8, and the negative value indicates horizontally left (or vertically downward), which is analyzed from the graph:

(1) The displacements of nos. 1-11 monitoring points are all negative value, which means that the bearing platform has a corresponding displacement under the superstructure load and surrounding rock bias pressure. In the later construction, it is necessary to backfill the left cavity of the bearing platform. 


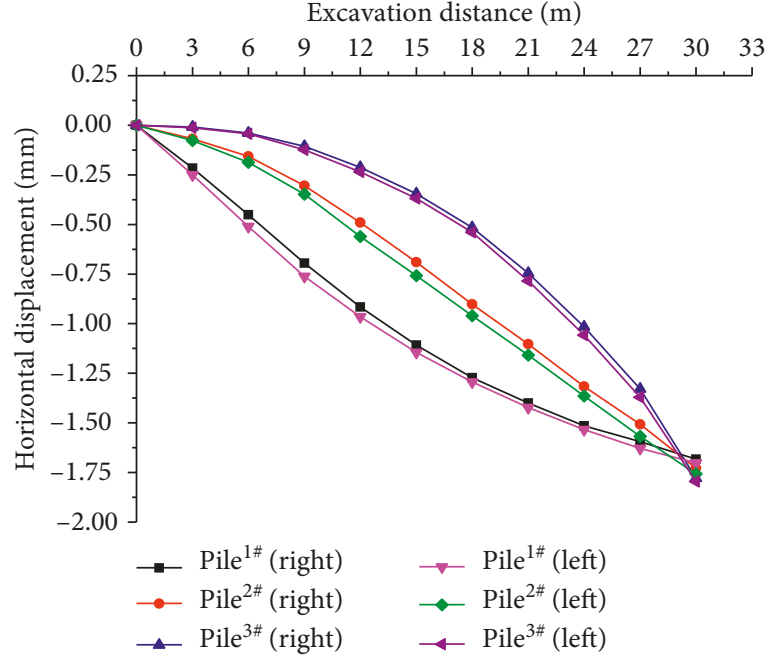

(a)

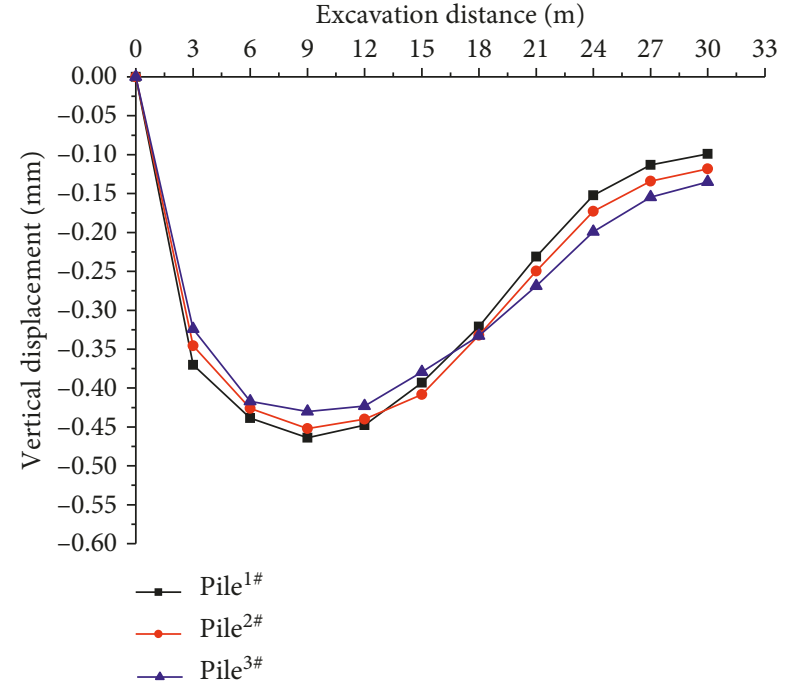

(b)

FIgURE 5: Displacement at the pile top under different excavation distances: (a) horizontal displacement; (b) vertical displacement.

Contour of ZZ-stress

Calculated by: volumetric averaging

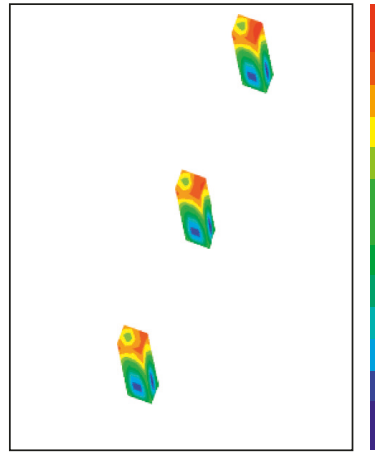

$3.0502 E+05$

$0.0000 E+00$

$-5.0000 E+05$

$-1.0000 E+06$

$-1.5000 E+06$

$-2.0000 E+06$

$-2.5000 E+06$

$-3.0000 E+06$

$-3.5000 E+06$

$-4.0000 E+06$

$-4.5000 E+06$

$-5.0000 E+06$

$-5.5000 E+06$

$-5.6091 E+06$
Contour of ZZ-stress

Calculated by: volumetric averaging

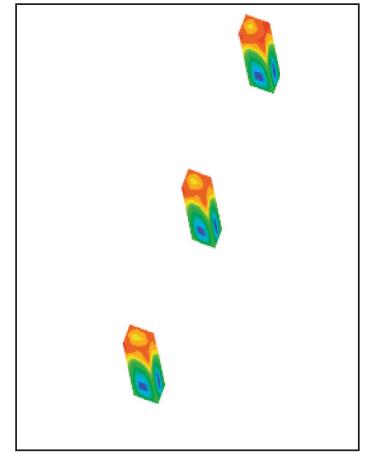

$-2.6106 E+05$

$-5.0000 E+05$

$-1.0000 E+06$

$-1.5000 E+06$

$-2.0000 E+06$

$-2.5000 E+06$

$-3.0000 E+06$

$-3.5000 E+06$

$-4.0000 E+06$

$-4.5000 E+06$

$-5.0000 E+06$

$-5.5000 E+06$

$-5.6142 E+06$

Figure 6: Vertical stress of the pile top. (a) Excavation of $9 \mathrm{~m}$. (b) Excavation of $24 \mathrm{~m}$.

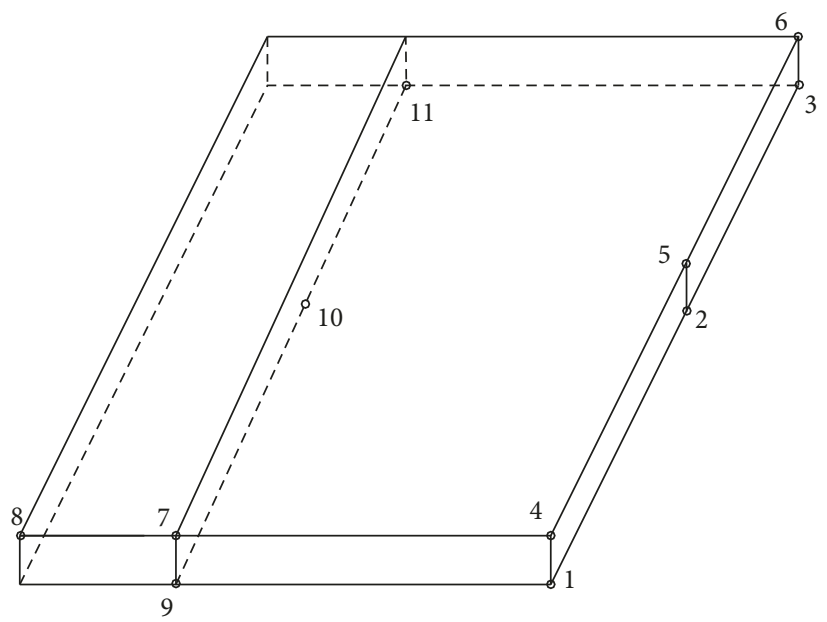

FIgURE 7: Layout of the measuring point in the platform. 


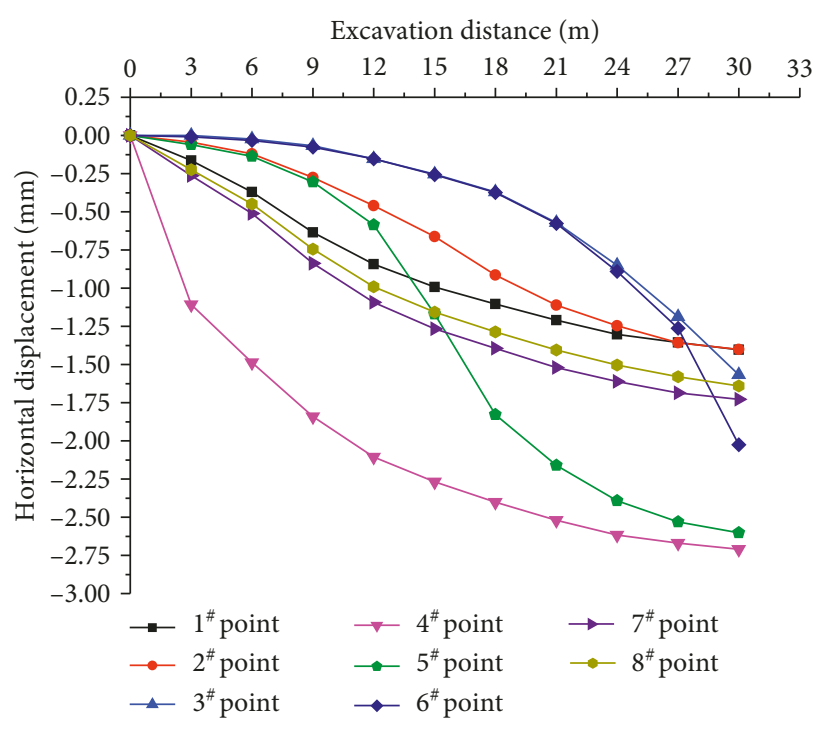

(a)

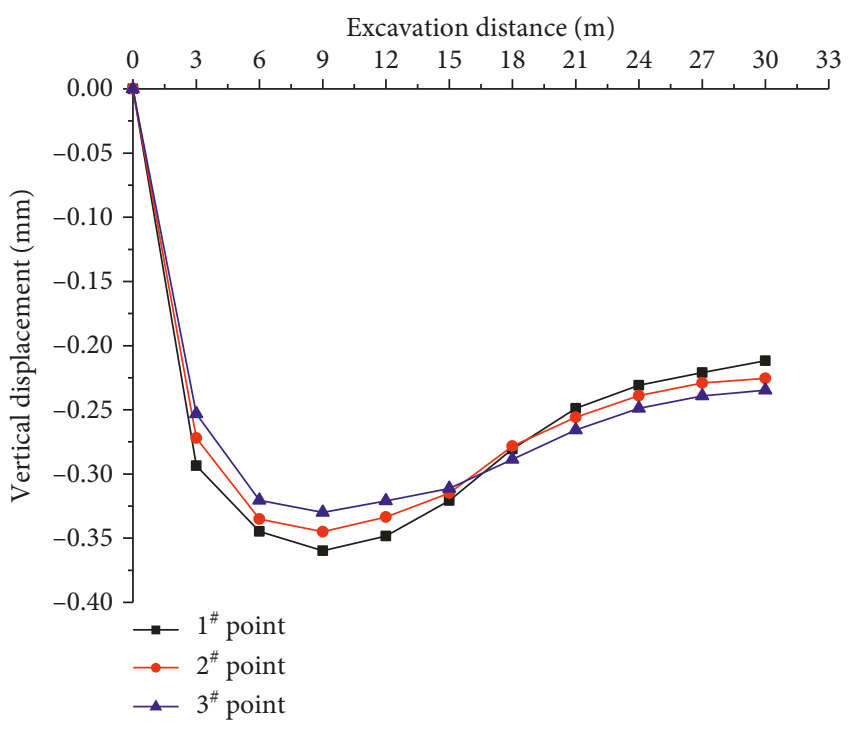

(b)

Figure 8: Displacement of the platform under different excavation distances: (a) horizontal displacement; (b) vertical displacement.

(2) The vertical displacement of the bearing platform is much smaller than the horizontal displacement, the horizontal displacement of top nos. 4 6 monitoring points is larger than that of bottom nos. 1 3, and the horizontal displacements of the monitoring points 4 , 7 , and 8 in the same section are successively decreased. The maximum horizontal displacement of the bearing platform is $2.7 \mathrm{~mm}$, which appears on the top right corner in no. 4 point.

(3) After the excavation, the influence of the surrounding rock on the right side on the bearing platform is more significant than the structure of the retaining wall. When the distance to excavation surface gets closer, the horizontal displacement of the bearing platform will become greater. The vertical displacement of points 9 to 11 of the bearing platform increased rapidly during the early stage of excavation; the displacement peak is reached when the excavation reaches $9 \mathrm{~m}$, and then it began to gradually decrease and tends to the value of $0.22 \mathrm{~mm}$ with construction progress. It can be seen that the impact of the construction on the vertical displacement of the bearing platform is $9 \mathrm{~m}$.

\subsection{Analysis of Retaining Wall Stress and Strain}

4.3.1. Analysis of Retaining Wall Displacement. Figure 9 shows the layout of the retaining wall feature points. Nos. 1-3 points are located at the intersection of the retaining wall and surrounding rock, and nos. 4-6 points are located at the middle of the right side of the retaining wall. According to the results of simulation calculation, the displacement of the monitoring point of the retaining wall is shown in Figure 10. A negative value indicates that the displacement is to the left (or vertically downwards), as analyzed from the figure:

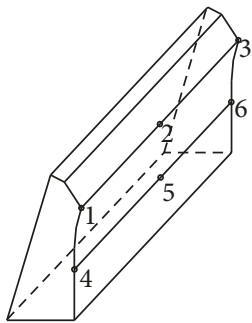

FIGURE 9: Retaining wall measuring point arrangement.

(1) The displacements of the feature points are all negative value, which reflecting the excavation construction produces a bias pressure effect. Meanwhile, it reflects that the retaining wall will play a supporting role under the bias of the surrounding rock.

(2) The vertical displacement of the retaining wall is less than the horizontal displacement, the horizontal displacement of the upper part is less than that of the middle part of the retaining wall, and the maximum value is $1.45 \mathrm{~mm}$ on no. 6 point; the vertical displacement of the left side of the retaining wall is smaller than that of the right side, and the maximum value is $0.62 \mathrm{~mm}$, which appears at the intersection of surrounding rock and retaining wall. Meanwhile, the vertical displacement of the bottom is also less than that of the other upper points.

(3) As the excavation progresses, the overall horizontal displacement of the retaining wall also gradually increases, and the displacement rate of the lower part is greater than that of the upper part; at the same excavation section, when the distance to excavation surface gets smaller, the horizontal displacement of the retaining wall will become greater, and the peak 


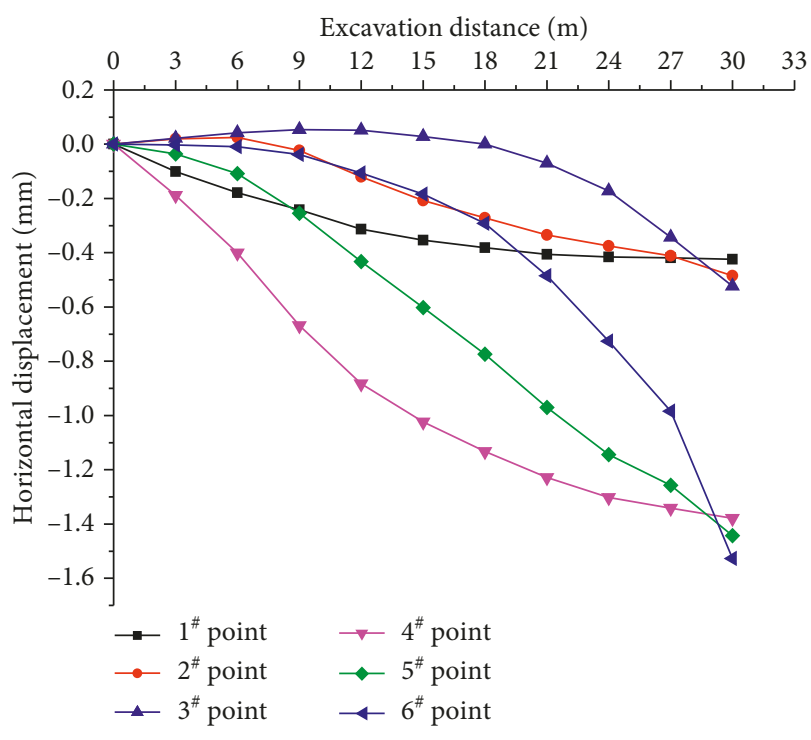

(a)

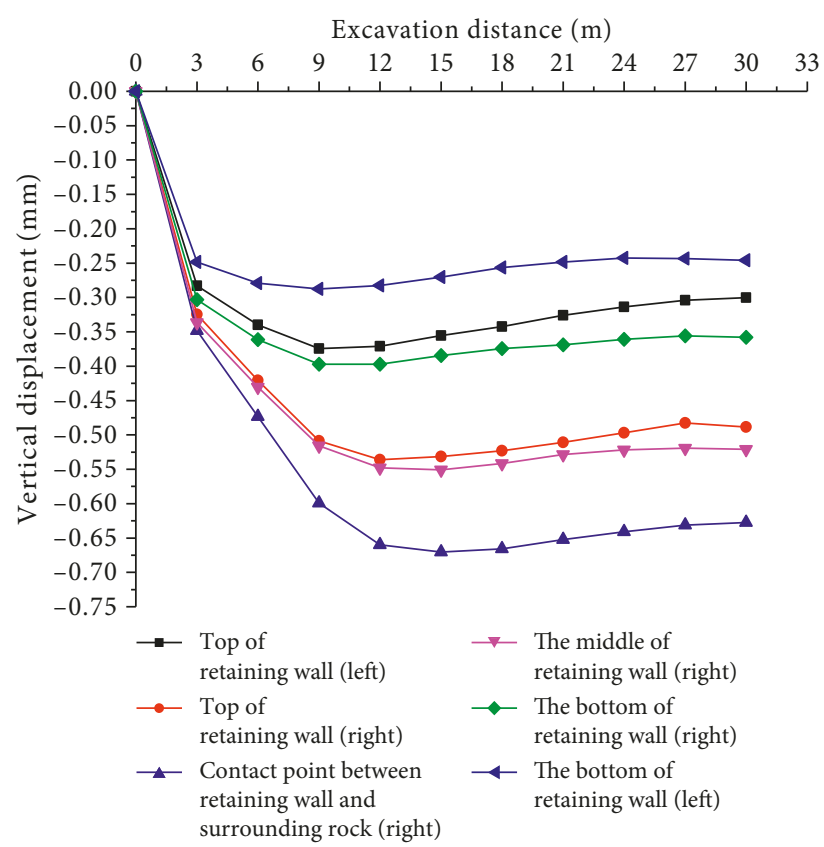

(b)

FIGURE 10: Displacement of the retaining wall at different excavation distances: (a) horizontal displacement; (b) vertical displacement.

value is reached after the completion of excavation. The vertical displacement rapidly increases during the initial period of excavation and reaches a maximum at $12 \mathrm{~m}$, and then it decreases and tends to a constant value. It can be seen that the range of influence of the construction on the vertical displacement of the retaining wall is about $12 \mathrm{~m}$.

4.3.2. Stress Analysis of the Retaining Wall. Figure 11 shows the stress changes of the retaining wall under four working conditions. Negative values indicate compressive stress, and positive values indicate tensile stress. The following can be seen from the figure:

(1) The maximum value of vertical compressive stress appears at the lower right corner of the retaining wall, with a maximum value of $3 \mathrm{MPa}$. At the same time, the vertical compressive stress changes from the initial $0.2 \mathrm{MPa}$ to the maximum $0.75 \mathrm{MPa}$ at the top of the retaining wall.

(2) From the view of dynamic construction, the vertical maximum compressive stress in the lower right corner of the retaining wall is gradually moved forward along the excavation direction, and the stress value also increases as the excavation distance increases and reaches the peak value when the excavation is completed.

(3) For the maximum compressive stress of the right lower corner of the retaining wall, the construction quality should be strengthened, and the stability of the connection between the bottom of the retaining wall and the bearing platform should be maintained. Meanwhile, for the trend of displacement to the left karst cave at the retaining wall, it is necessary to backfill the left karst cave with a backpressure to keep the overall structure stable after the completion of the construction.

4.4. Displacement Analysis of Tunnel Surrounding Rock. Figure 12 shows the displacement change of the surrounding rock of the tunnel at the excavation section $Y=0$, in which the positive value indicates the horizontal direction to the right (vertically upward) and the negative value indicates the horizontal direction to the left (vertically down), as analyzed from the figure:

(1) After excavation, the horizontal displacement of the right side wall and right arch of the tunnel appears convergent to the left with the maximum of $2.56 \mathrm{~mm}$. The rest of the monitoring points are horizontally offset to the right, and the maximum rightward displacement appears in the vault of $2.8 \mathrm{~mm}$.

(2) The vertical displacement of surrounding rock is far greater than the horizontal displacement, and there is a large upward displacement of $4.5 \mathrm{~mm}$ at the right arch foot of the tunnel. The vertical displacement of the rest of the feature points is all settlement, and the maximum of vertical settlement of $4.6 \mathrm{~mm}$ appears in the vault. The settlement of the right arch waist is larger than that of the left arch waist, which proves that the supporting structure of the left retaining wall plays a key role in suppressing the vertical displacement.

(3) As the excavation progresses, the vertical and horizontal displacements of each monitoring point increase with the increase of excavation distance. 
Contour of ZZ-stress

Calculated by: volumetric averaging

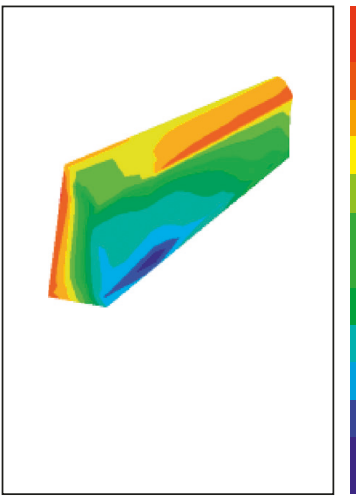
$3.5879 E+05$
$3.0000 E+05$
$2.0000 E+05$
$1.0000 E+05$
$0.0000 E+00$
$-1.0000 E+05$
$-2.0000 E+05$
$-3.0000 E+05$
$-4.0000 E+05$
$-5.0000 E+05$
$-6.0000 E+05$
$-7.0000 E+05$
$-7.7028 E+05$

(a)

Contour of ZZ-stress

Calculated by: volumetric averaging

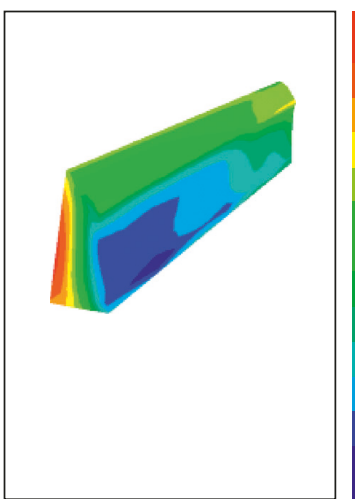
$1.2213 E+06$
$1.0000 E+06$
$7.5000 E+05$
$5.0000 E+05$
$2.5000 E+05$
$0.0000 E+00$
$-2.5000 E+05$
$-5.0000 E+05$
$-7.5000 E+05$
$-1.0000 E+06$
$-1.2500 E+06$
$-1.5000 E+06$
$-1.7500 E+06$
$-1.9843 E+06$

(c)
Contour of ZZ-stress

Calculated by: volumetric averaging

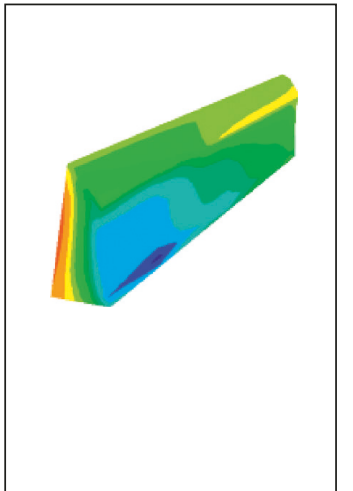

$8.3343 E+05$

$8.0000 E+05$

$6.0000 E+05$

$4.0000 E+05$

$2.0000 E+05$

$0.0000 E+00$

$-2.0000 E+05$

$-4.0000 E+05$

$-6.0000 E+05$

$-8.0000 E+05$

$-1.0000 E+06$

$-1.2000 E+06$

$-1.4000 E+06$

$-1.4412 E+06$

(b)

Contour of ZZ-stress

Calculated by: volumetric averaging

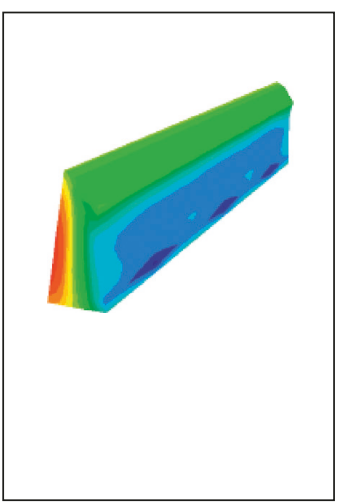

$1.4284 E+06$

$1.2500 E+06$

$1.0000 E+06$

$7.5000 E+05$

$5.0000 E+05$

$2.5000 E+05$

$0.0000 E+00$

$-2.5000 E+05$

$-5.0000 E+05$

$-7.5000 E+05$

$-1.0000 E+06$

$-1.2500 E+06$

$-1.5000 E+06$

$-1.7500 E+06$

$-2.0000 E+06$

$-2.5000 E+06$

$-3.0000 E+06$

(d)

FIGURE 11: Vertical stress change of the retaining wall under different working conditions: (a) excavation of $3 \mathrm{~m}$; (b) excavation of $12 \mathrm{~m}$; (c) excavation of $21 \mathrm{~m}$; (d) excavation of $30 \mathrm{~m}$.

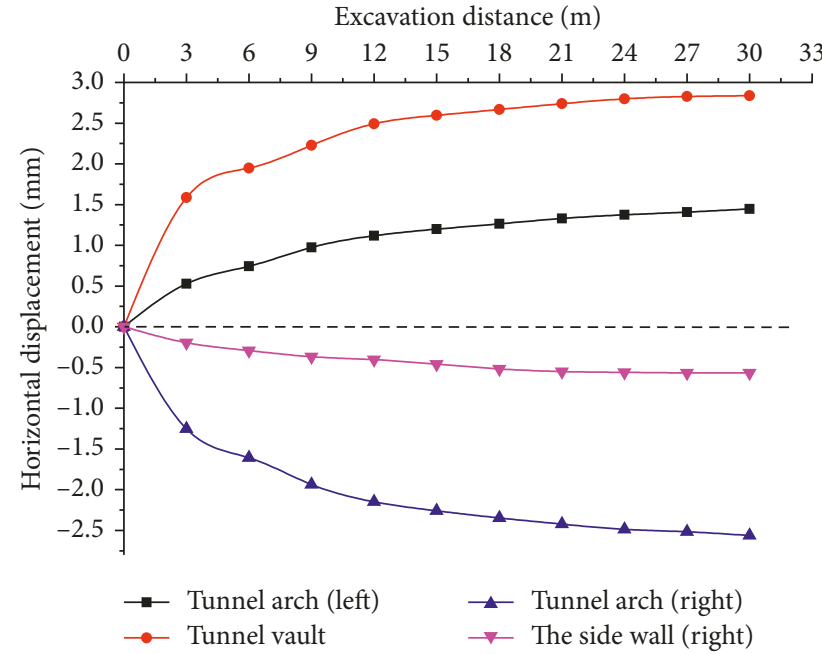

(a)

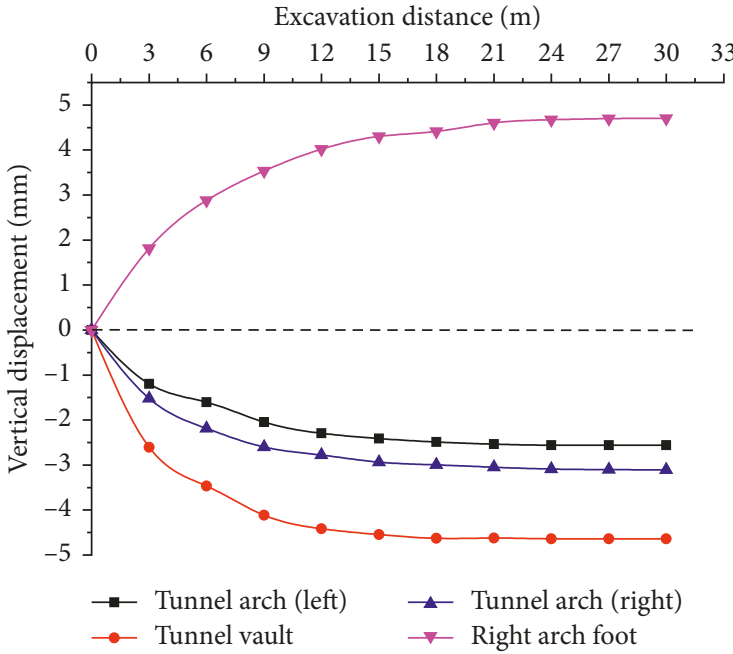

(b)

FIGURE 12: Displacement of surrounding rock of the tunnel under different working conditions: (a) horizontal displacement; (b) vertical displacement. 


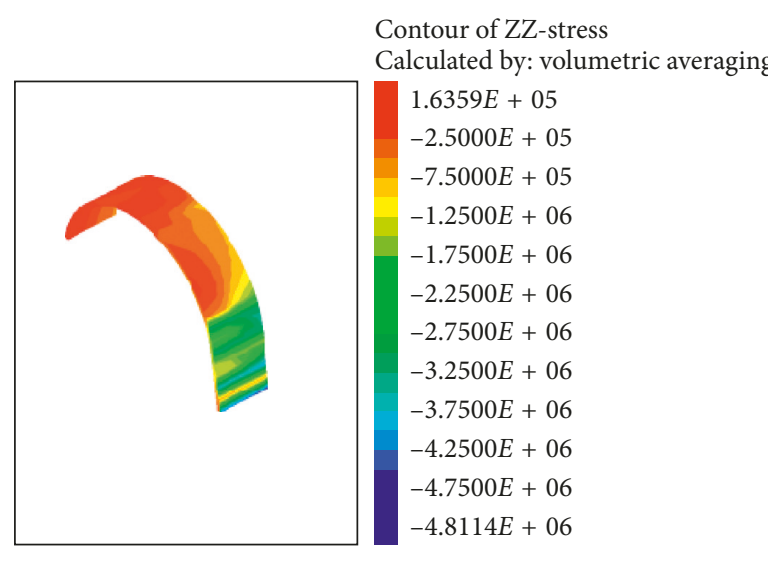

(a)

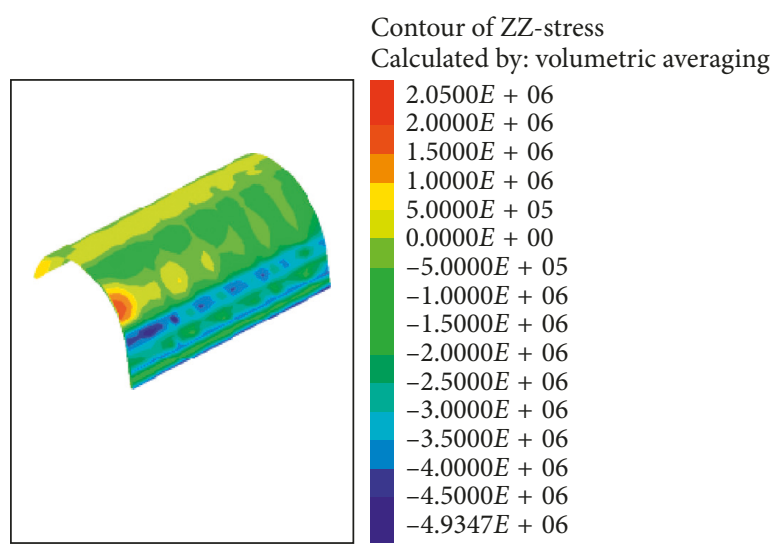

(c)

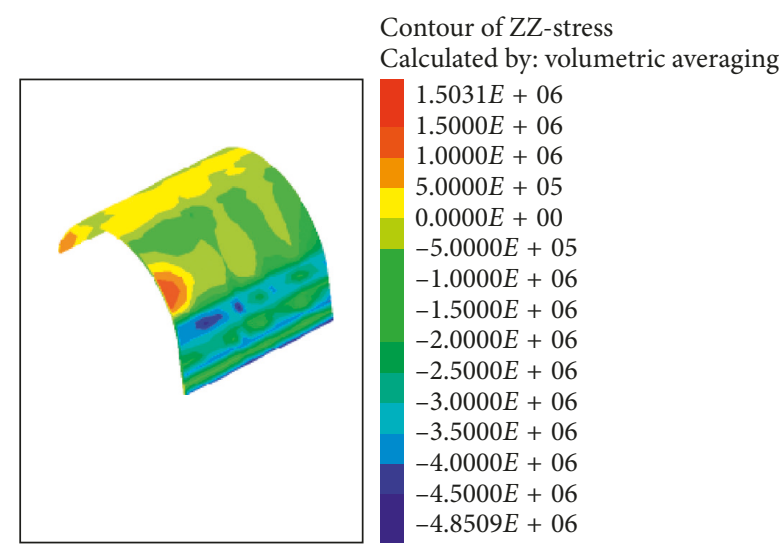

(b)

Contour of ZZ-stress

Calculated by: volumetric averaging

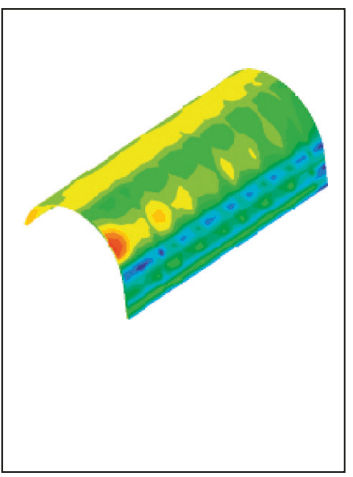

$2.2248 E+06$ $2.0000 E+06$ $1.5000 E+06$ $1.0000 E+06$ $5.0000 E+05$ $0.0000 E+00$ $-5.0000 E+05$

$-1.0000 E+06$

$-1.5000 E+06$

$-2.0000 E+06$

$-2.5000 E+06$

$-3.0000 E+06$

$-3.5000 E+06$

$-4.0000 E+06$

$-4.5000 E+06$

$-5.0000 E+06$

$-5.0491 E+06$

(d)

FiguRE 13: Vertical stress of tunnel surrounding rock under different excavation distances: (a) excavation of $3 \mathrm{~m}$; (b) excavation of $12 \mathrm{~m}$; (c) excavation of $21 \mathrm{~m}$; (d) excavation of $30 \mathrm{~m}$.

After excavation of $15 \mathrm{~m}$, the change rate decreased and gradually tended to stable. It can be seen that the range of influence of tunnel excavation on the front section is $15 \mathrm{~m}$.

4.5. Stress Analysis of the Initial Support. Figure 13 shows the vertical stress of the initial support structure under different tunneling footage. The negative value represents the compressive stress, and the positive value represents the tensile stress, as analyzed from the figure:

(1) During the excavation process, the stress of the initial lining support gradually increases with the increase of the excavation distance. The overall structure is mainly presented as a compressive stress, and the maximum compressive stress of $5 \mathrm{MPa}$ appears at the support point on the right wall of the tunnel and the right arch foot. The compressive stress value of the whole support is $1 \sim 5 \mathrm{MPa}$, which is far less than the ultimate compressive strength of $15.4 \mathrm{MPa}$ of C20 shotcrete, which indicates that the initial support structure is safe and stable.

(2) From the results of the final stress, it can be seen that there is a tensile stress of 1 to $2 \mathrm{MPa}$ at the right arch position of the initial support structure, and at the same time, there is a stress difference between each section of support, so the quality of the connection between the supporting structures in each cycle tunneling footage should be enhanced. Meanwhile, the quality and thickness of the initial support should be increased in the stress concentration area of the right side wall.

\section{Field Test Analysis}

5.1. Stability Test and Analysis of the Pile Foundation. The pile top strain test adopted the JMZX-215A intelligent embedded concrete strain gauge, and the strain gauge was placed on the top of the main reinforcement of the pile to test the concrete strain at the top of the pile before the pile was poured. Figure 14 shows the test conditions of no. 2 pile foundation below the field-retaining wall foundation:

It can be seen from Figure 14 that a negative strain value was produced at the pile head, indicating that the superstructure loads and the excavation have produced compressive stress. In 1 to 10 days, small vertical strains of the pile head were generated due to the concrete pouring of the bearing platform. The next 11 25 days, the vertical strains of 


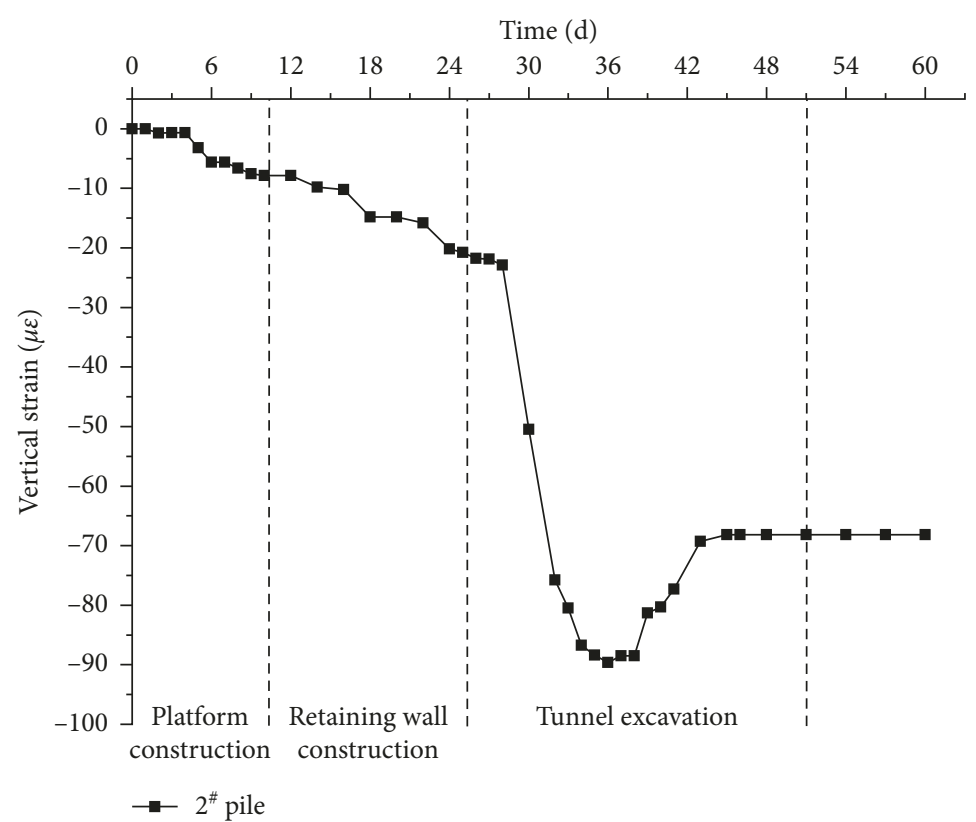

(a)

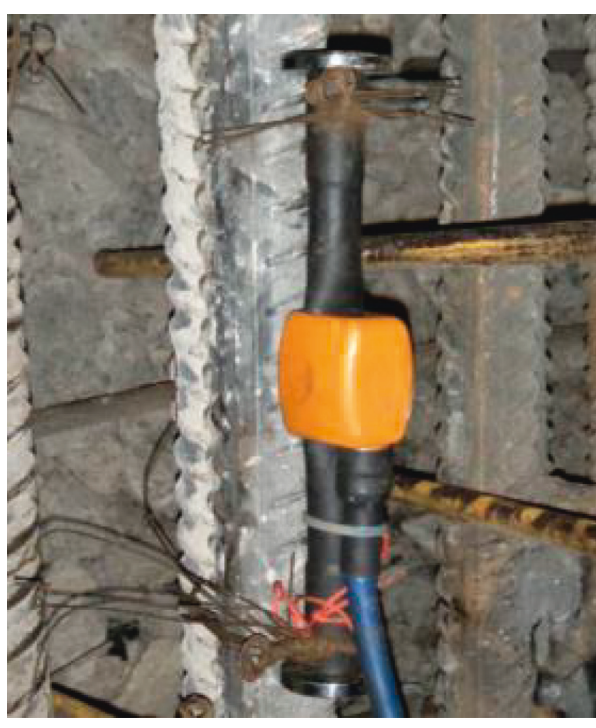

(b)

Figure 14: Strain test of the pile. (a) Vertical strain of no. 2 pile top. (b) Site installation.

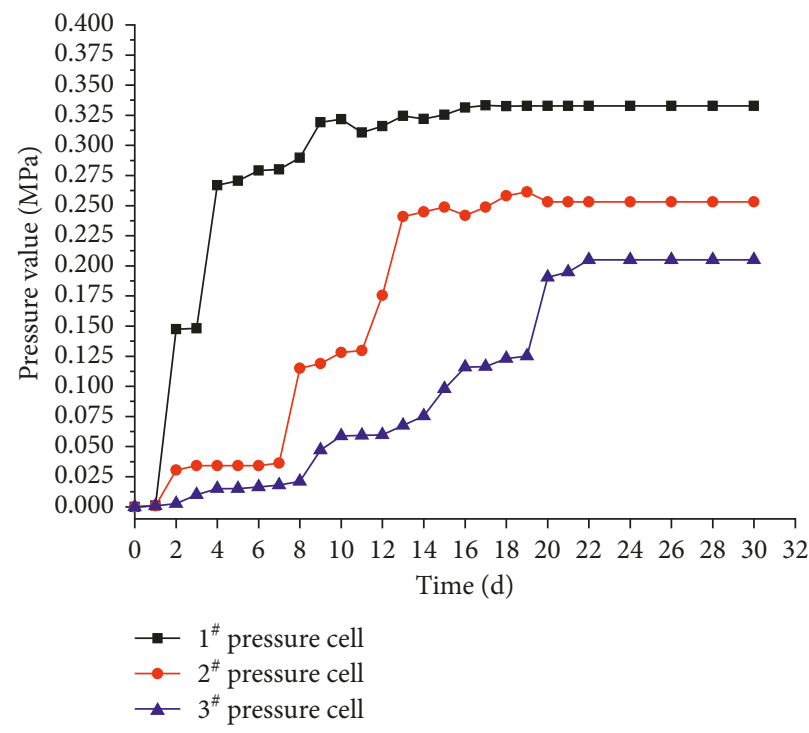

(a)

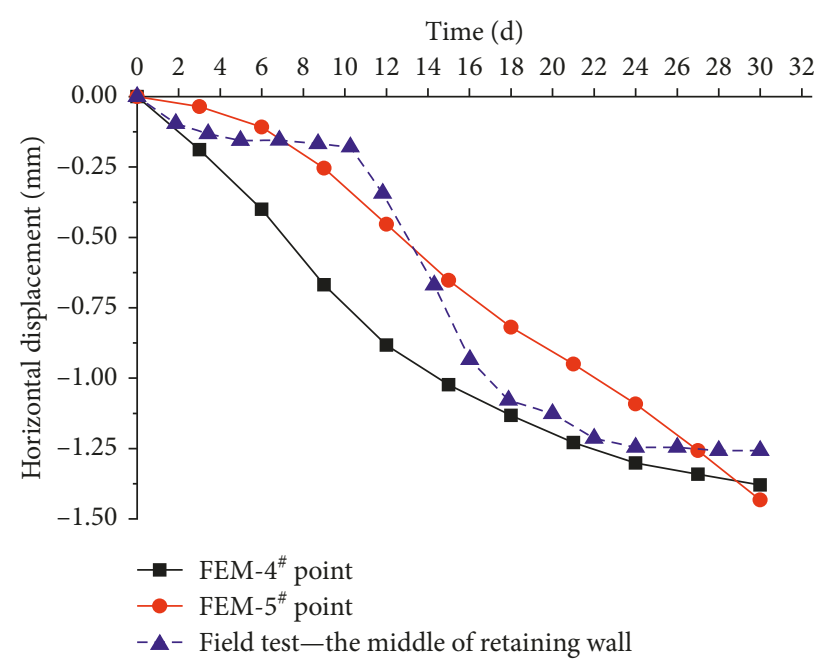

(b)

Figure 15: Pressure test of the retaining wall. (a) Relationship between retaining wall pressure and time. (b) Horizontal displacement in the middle of the retaining wall.

the pile head increased slowly as the concrete layered pouring of the retaining wall. And the vertical strain rate of the pile increased rapidly after 29 days, indicating that the upper retaining wall structure was affected by the pressure subjected to the surrounding rocks, and thus, the pressure of the bearing platform and the pile head was also produced, which made the strain of the pile increase rapidly. At the end of the excavation, the vertical strain of the pile began to decrease gradually and became stable with the completion of the construction, indicating that the pile foundation structure was stable.
5.2. Stability Test and Analysis of the Retaining Wall. The stress test at the junction of the retaining wall and the surrounding rock of the karst cave was based on the JMZX5010am intelligent pressure cell and the JMDL-3210A singlepoint displacement meter. Figure 15(a) shows the test results of 3 pressure cells in the front, middle, and rear of the top of the retaining wall, while Figure 15(b) shows the test result of the horizontal displacement meter in the middle point of the retaining wall. Information available from Figure 15 is given below. 


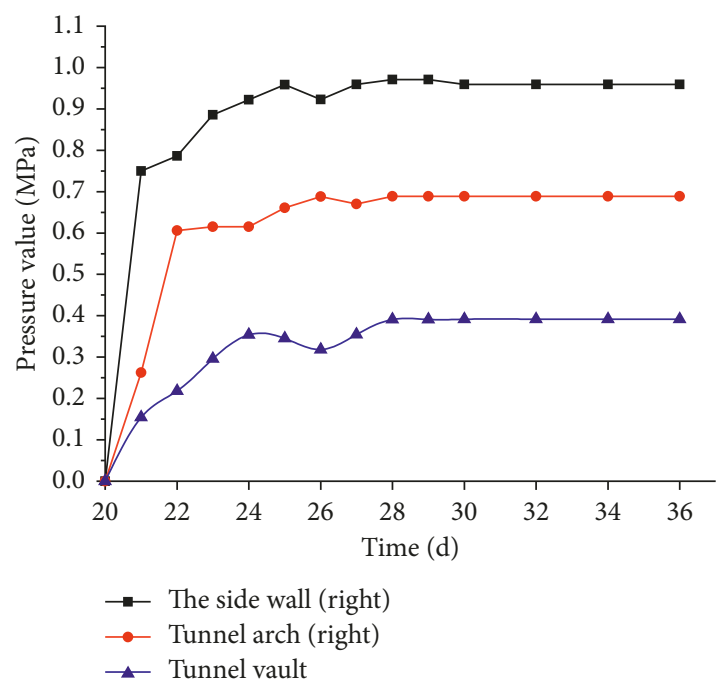

(a)

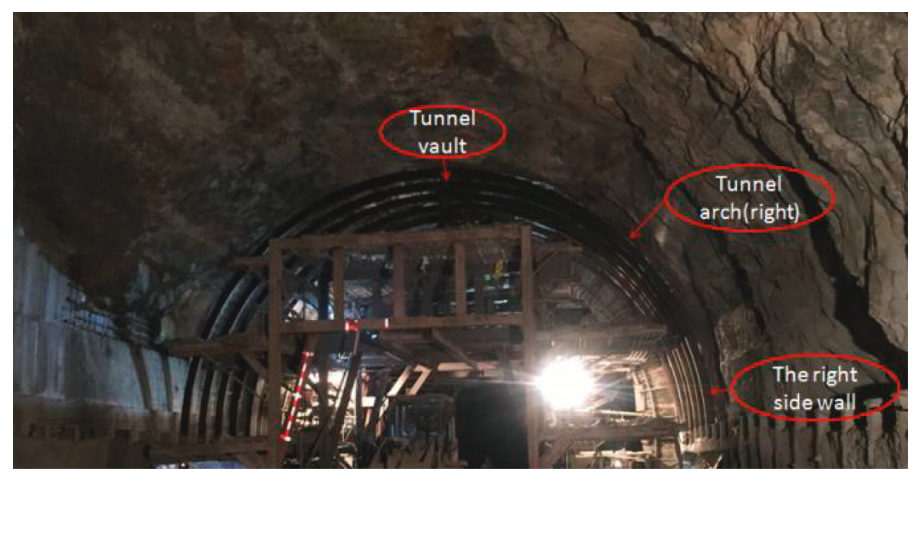

(b)

FIGURE 16: Displacement test of surrounding rock. (a) Change in surrounding rock and initial lining pressure of the K14 + 400 section. (b) Site layout.

In Figure 15(a), when the excavation was carried out, the surrounding rock pressure acting on no. 1 pressure cell was increased rapidly, and the rate of change reached $0.15 \mathrm{MPa} / \mathrm{d}$ and increased to $0.27 \mathrm{MPa}$ within 2 to 3 days. In contrast, the pressure change of nos. 2 and 3 pressure cells was lagging behind, and an obvious increment in the 8th and 20th days started to generate. The pressure values of all the above three pressure cells tended to be stable finally, indicating that the confining pressure was basically stable after excavation. In Figure 15(b), the horizontal displacements of the retaining wall increased totally as the excavation distance increased. The horizontal displacements at the midpoint of the retaining wall structure during the initial excavation were small but increased at a rate of $0.25 \mathrm{~mm} / \mathrm{d}$ as the excavation surface was approaching, finally slowed down, and tended to a stable value in the 18 th day. In summary, the maximum pressure of the retaining wall of $0.33 \mathrm{MPa}$ and the measured leftward horizontal displacement value of midpoint of $1.25 \mathrm{~mm}$ are all smaller than the simulation results. It can be seen that the stress released by the stress redistribution of the surrounding rock due to the surface excavation was small.

\subsection{Structure Test and Analysis of the Initial Support.} JMZX-5040am dual-mode pressure cells were, respectively, installed on the tunnel vault, tunnel arch (right), and right side wall of the $\mathrm{K} 14+400$ section to test the pressure change between the surrounding rock and the initial support.

As shown in Figure 16, after the initial support was constructed, the pressure value of the lining increased with the following excavation, and the change rate at the characteristic point of the right side wall increased fastest and reached a maximum value of $0.95 \mathrm{MPa}$. The pressure of the tunnel vault acting on the lining structure had the minimum value of $0.39 \mathrm{MPa}$, which indicated that the right confining pressure of surrounding rock had great influence on the right side wall. The bias pressures of the three measuring points were far less than the ultimate compressive strength of the initial lining, so we concluded the lining structure was stable. Furthermore, the pressure change rate was almost close to zero in the 28th day, indicating that the deformation of the surrounding rock was stopped. From the above analysis, the stability period of surrounding rock in this tunnel section was inferred in 28 30 days.

5.4. Displacement Test and Analysis of Surrounding Rock. The internal displacement of the surrounding rock test of the $\mathrm{K} 14+385$ section was conducted using a JMDL-3210A single-point displacement meter, and its specifications were $1.5 \mathrm{~m}, 2.5 \mathrm{~m}$, and $3.5 \mathrm{~m}$, respectively. The settlement test and convergence test of the tunnel vault were performed with level measurement and a JSS30A aggregator, respectively. As shown in Figure 17, a positive value represents the displacement of the surrounding rock was biased toward the inside of the tunnel, and a negative value indicated the tunnel vault had a settlement and tended to convergence.

(1) Both the internal displacement and convergence of the surrounding rock had a tendency of coming toward the inside of the tunnel. The displacement of the surrounding rock at internal $1.5 \mathrm{~m}$ was larger than that at other two measuring points, which is $1.4 \mathrm{~mm}$, while the internal displacement of the surrounding rock at $3.5 \mathrm{~m}$ is the smallest, of $0.79 \mathrm{~mm}$, which indicates the closer the measuring point near the loose circle, the bigger the displacement of the measuring point would be, and vice versa.

(2) The displacement change rate of surrounding rock during the initial stage of construction was relatively large, and the change rate gradually decreases with the passage of construction time. After the 22nd day, 


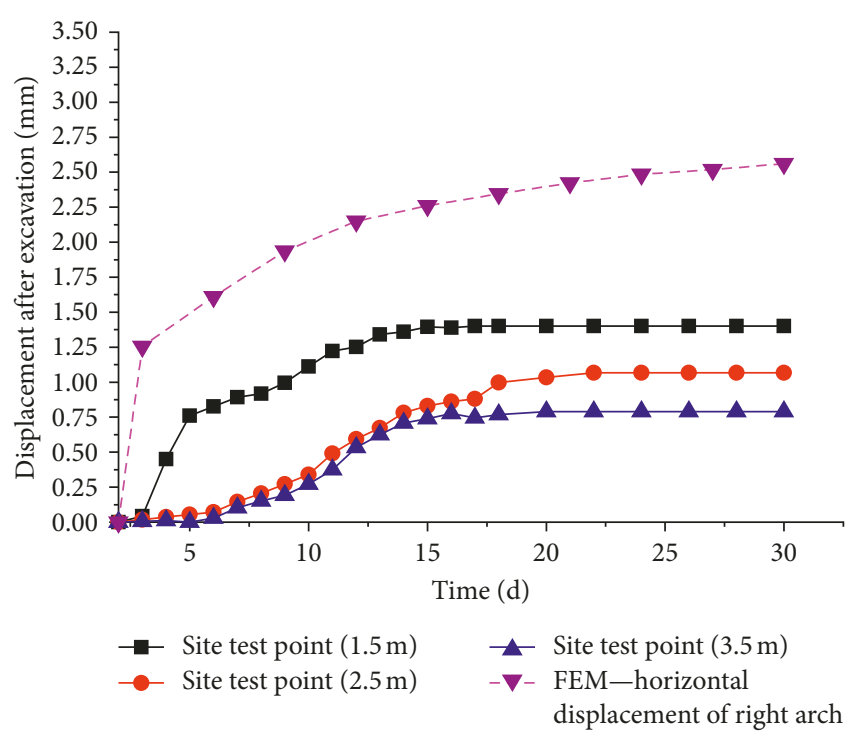

(a)

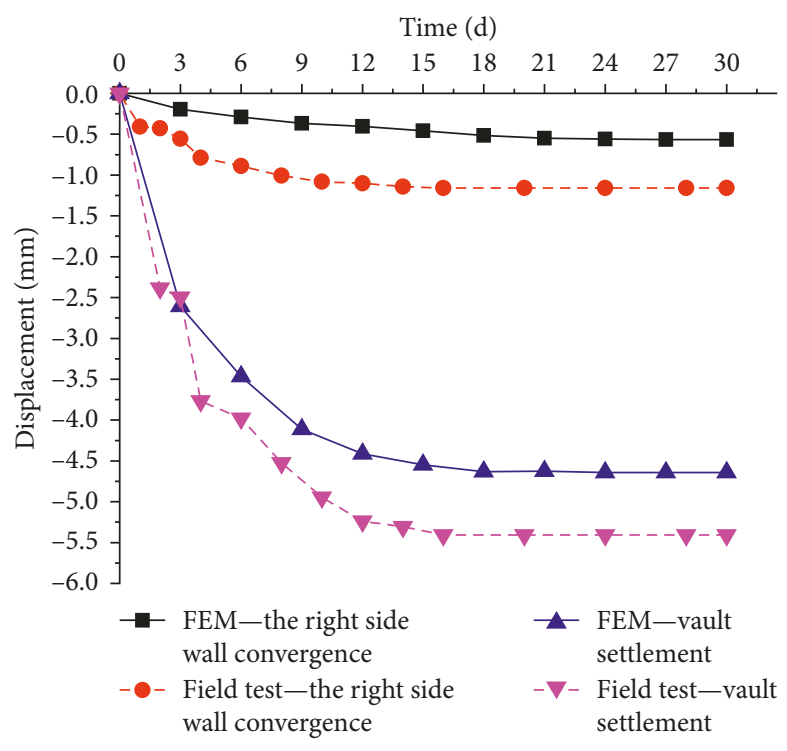

(b)

Figure 17: Displacement test of surrounding rock. (a) Internal displacement of surrounding rock of the K14+385 section. (b) Dome settlement and peripheral convergence of the K14 +385 section.

TABle 2: Comparison between field test results and numerical simulation results.

\begin{tabular}{lcc}
\hline & Field test results (max) & Numerical simulation results (max) \\
\hline Top pressure value of the pile & $2 \mathrm{MPa} \sim 2.5 \mathrm{MPa}$ & $2.5 \mathrm{MPa} \sim 3.5 \mathrm{MPa}$ \\
Pressure value between surrounding rock and & $0.2 \mathrm{MPa} \sim 0.33 \mathrm{MPa}$ & $0.5 \mathrm{MPa} \sim 0.75 \mathrm{MPa}$ \\
retaining wall & $5 \sim 6.5 \mathrm{~mm}$ & $4.6 \mathrm{~mm}$ \\
Settlement value of the vault & $1.0 \mathrm{~mm} \sim 1.2 \mathrm{~mm}$ & $0.5 \mathrm{~mm}$ \\
Tunnel convergence value & $0.79 \mathrm{~mm} \sim 1.4 \mathrm{~mm}$ & $2.5 \mathrm{~mm}$ \\
Displacement of the surrounding rock of the right & $0.95 \mathrm{MPa}$ & $1 \mathrm{MPa} \sim 5 \mathrm{MPa}$ \\
Initial support pressure value & & \\
\hline
\end{tabular}

the change of displacement of the whole surrounding rock was basically zero, which indicated that surrounding rock reached a stable state and the change period of the surrounding rock displacement in this section is $22 \sim 25$ days.

\subsection{Comparison of Field Test and Calculation Simulation.} Comparison between field tests and numerical simulation results is given in Table 2, and it shows the following:

(1) Compared with the results of field tests and numerical simulations, the stress and strain change laws of each structure during the excavation stage were basically the same. The displacement error was less than $2 \mathrm{~mm}$, and the stress error was less than $1 \mathrm{MPa}$. There is a great agreement between the field test results and simulation results.

(2) The strain test results of the pile head were slightly smaller than the simulation results. Meanwhile, there was no large offset and settlement in the overall structure of the site, which proved that the design of the pile foundation was reasonable and applicable.
(3) The pressure at the top of the retaining wall on the site as well as the displacement at the midpoints was smaller than the simulation results, indicating that the actual surrounding rock pressure is lower than the design value. At the same time, according to the onsite observation, the roof of the karst cave had not collapsed and become unstable after the treatment structure construction, which verified that the supporting effect of the backfill pile foundation-bearing platform-retaining wall-combined supporting structure was good.

(4) Due to the relative lagging nature of the on-site support process, the settlement and convergence of the tunnel vault on-site were larger than the simulation results by 1 to $2 \mathrm{~mm}$. Combined with the results of the field test and numerical simulation, there were no large displacement changes; thus, the stability of the surrounding rock of the superlarge karst cave was reflected as good from another point of view.

(5) There may be no sufficient contact between the pressure cell and the surrounding rock, which led to 
the result that both the pressure of the initial support and the pressure of the surrounding rock were less than the simulation results. The maximum surrounding rock pressure stress appeared on the right wall on the site, which was far less than the ultimate compressive strength of the design of the support. Also, the deformation of the arch foot did not appear in the field, which reflected the supporting effect was good.

\section{Conclusion}

Both the characteristics and change laws of stress and strain of the surrounding rock and treatment structures in the superlarge karst cave of Naqiu Tunnel were discussed under different excavation distances situation. The following conclusions can be drawn from the comparison between field tests and numerical simulation:

(1) During the excavation, the top of the pile foundation produced a larger leftward displacement under the bias pressure of surrounding rock, which increases with the excavation distance. The vertical displacement is less than the horizontal displacement and gradually decreases after the excavation of $9 \mathrm{~m}$. The influence scope of overall excavation on the pile foundation is $9-10 \mathrm{~m}$.

(2) The bearing platform and the retaining wall also produced a leftward displacement under the bias pressure. The effect of excavation on the horizontal displacement is much larger than that on the vertical displacement. A large stress concentration appears in the lower right corner of the retaining wall, and the stability of the connection between the bottom structure of the retaining wall and the bearing platform should be maintained during construction. At the same time, to ensure the stability of the operation in the future, backfill is needed for the left karst cave in the later stage of construction.

(3) Compared with the horizontal displacement, the vertical displacement of the surrounding rock around the tunnel was greater, and the maximum vertical settlement of $4.6 \mathrm{~mm}$ appeared at the tunnel vault. The settlement of the tunnel arch (right) was larger than that of the left arch, and it proved that the left retaining wall support structure contributed a restraining effect to the vertical displacement. With the construction progresses, the horizontal and vertical displacements became greater with the increase of the excavation distance, and the rate of change decreased and gradually became stable after excavation of $15 \mathrm{~m}$; it can be referred the influence scope of the surrounding rock excavation was $15 \mathrm{~m}$.

(4) The maximum compressive stress value of the supporting structure is far less than its ultimate compressive strength, and the supporting effect is proved to be good based on on-site testing and observation.
(5) The results of numerical simulation and field tests proved that the combined treatment structure of backfill pile foundation-bearing platform-retaining wall initial lining structure in the steep slope was stable and reasonable, and it can effectively restrain the bias pressure effect of surrounding rock, which can provide theoretical basis and construction reference for similar projects in the future.

\section{Data Availability}

The data used to support the findings of this study are available from the corresponding author upon request.

\section{Conflicts of Interest}

The authors declare that they have no conflicts of interest.

\section{Acknowledgments}

This work was supported by the National Natural Science Foundation of China (Grant nos. 51478479 and 51678570) and Hunan Transport Technology Project (Grant no. 201524).

\section{References}

[1] H. Kairong, "Development and prospects of tunnels and underground works in China in recent two years," Tunnel Construction, vol. 37, no. 2, pp. 123-134, 2017.

[2] W. Fumin, W. Mengjun, and L. Ke, "Look through tunnels through mountains and rivers-a summary of the achievement of the "Twelfth Five-Year" highway tunnel construction and the development prospect of the "Thirteenth Five-Year Plan"," China Highway, vol. 7, pp. 52-55, 2016.

[3] L. Xiongzhou, "Study on treatment technology of karst section of a highway tunnel in Yunnan Province," Chinese Journal of Underground Space and Engineering, vol. 13, no. S1, pp. 433-441, 2017.

[4] K. Yong, Y. Chunhe, and Z. Peng, "Disaster-induced mechanism and its treatment in shallow-buried karst tunnel," Chinese Journal of Rock Mechanics and Engineering, vol. 29, no. 1, pp. 149-154, 2010.

[5] W. Mengjun, X. Xibin, Z. Mingjie, and L Xuhua, "Construction mechanics response study of highway tunnel in karst," Chinese Journal of Rock Mechanics and Engineering, vol. 23, no. 9, pp. 1525-1529, 2004.

[6] M. Yangchun and Z. Xiaojun, "Stability analysis of surrounding rock of karst tunnel in Dacheng high speed railway," China Railway Science, vol. 29, no. 3, pp. 52-57, 2008.

[7] L. Yuanhai, Y. Su, Y. Jun, and G. Kunrong, "Influence of a large karst cave on rock mass stability during tunnelling," Modern Tunnelling Technology, vol. 53, no. 4, pp. 52-60, 2016.

[8] Z. Xianju and W. Mengtao, "Numerical simulation analysis on stability of karst tunnel surrounding rock and support," Highway Engineering, vol. 42, no. 2, pp. 170-173, 2017.

[9] Y. Peiguo and Z. Huajun, "Excavation deformation and support countermeasure of cave body in karst area," Construction Technology, vol. 46, no. 13, pp. 138-140, 2017.

[10] L. Shubin, F. Yong, Z. Chaoyue, and D. Ruyong, "Model test of tunnel excavation stability influenced by concealed cave with internal water pressure," Chinese Journal of Rock Mechanics and Engineering, vol. 2, no. s2, 2017. 
[11] F. Helin and X. Yi, "The research of oversize hall type karst of scheme comparison in tunnel," Journal of Hunan University of Arts and Science, vol. 3, pp. 42-46, 2015.

[12] Y. Dingyuan and F. Helin, "Study on treatment technology for gallery hall karst cave of highway tunnel," Highway Engineering, vol. 40, no. 3, pp. 185-191, 2015.

[13] X. Ming, Y. Chao, and F. Zhihao, "Three-dimensional numerical simulation and analysis of excavation and support in underground tunnel," Rock and Soil Mechanics, vol. 28, no. 12, pp. 2501-2505, 2007.

[14] Q. Wanbo, L. Xinrong, F. Yan, and Q. Xiaoying, "Numerical simulation of preliminary lining of large section crossing tunnels constructed with PBA method," Rock and Soil Mechanics, vol. 30, no. 9, pp. 2799-2804, 2009. 


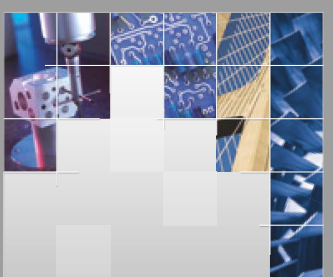

\section{Enfincering}
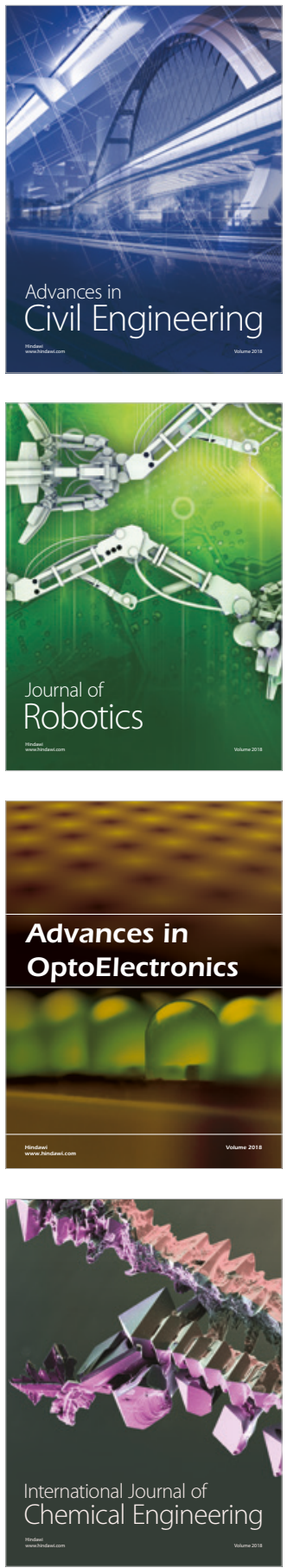

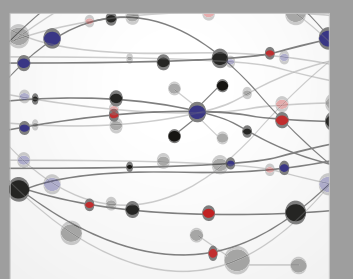

\section{Rotating \\ Machinery}

The Scientific World Journal

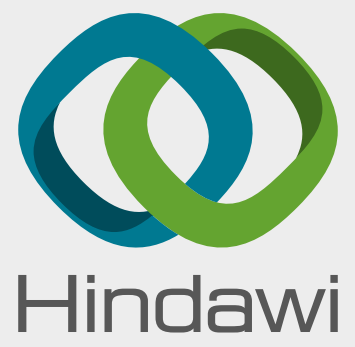

Submit your manuscripts at

www.hindawi.com
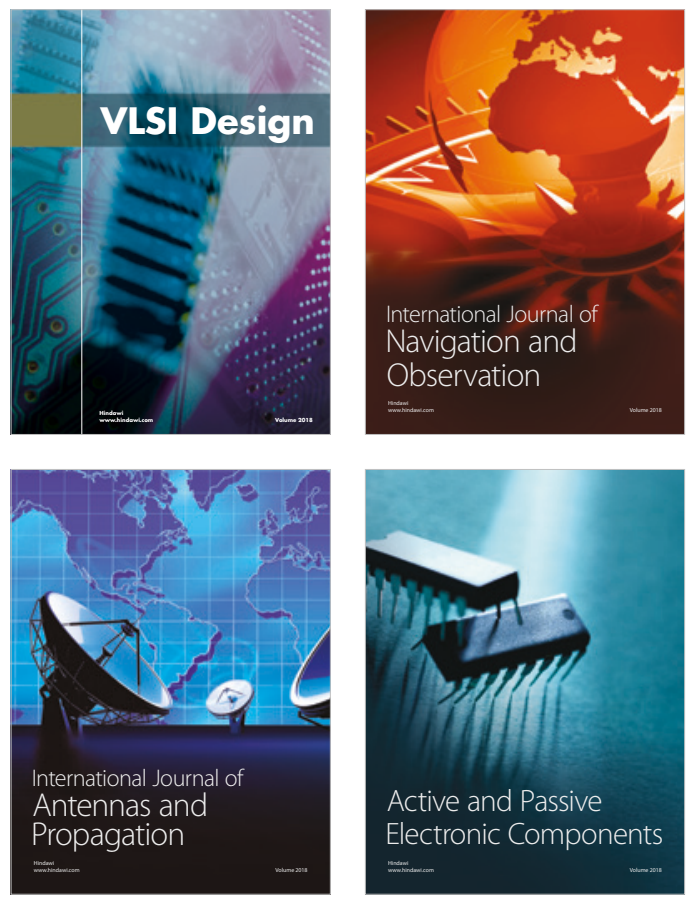
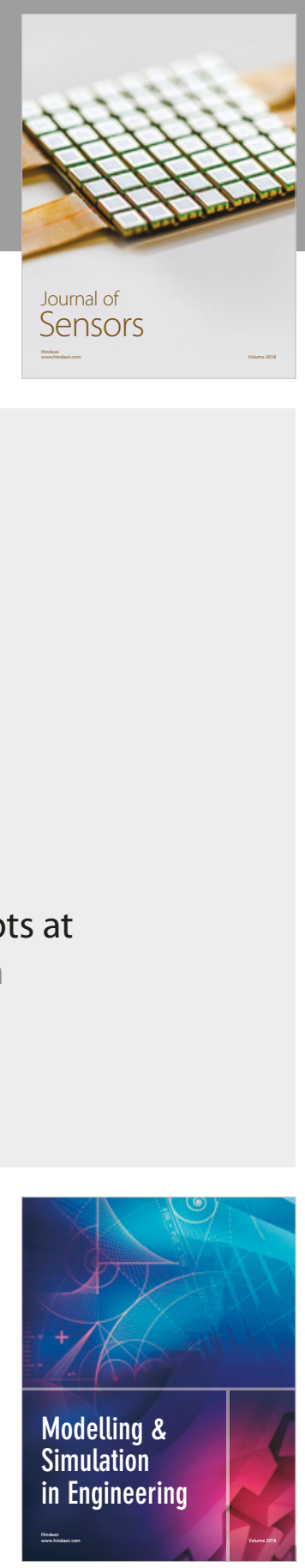

\section{Advances \\ Multimedia}
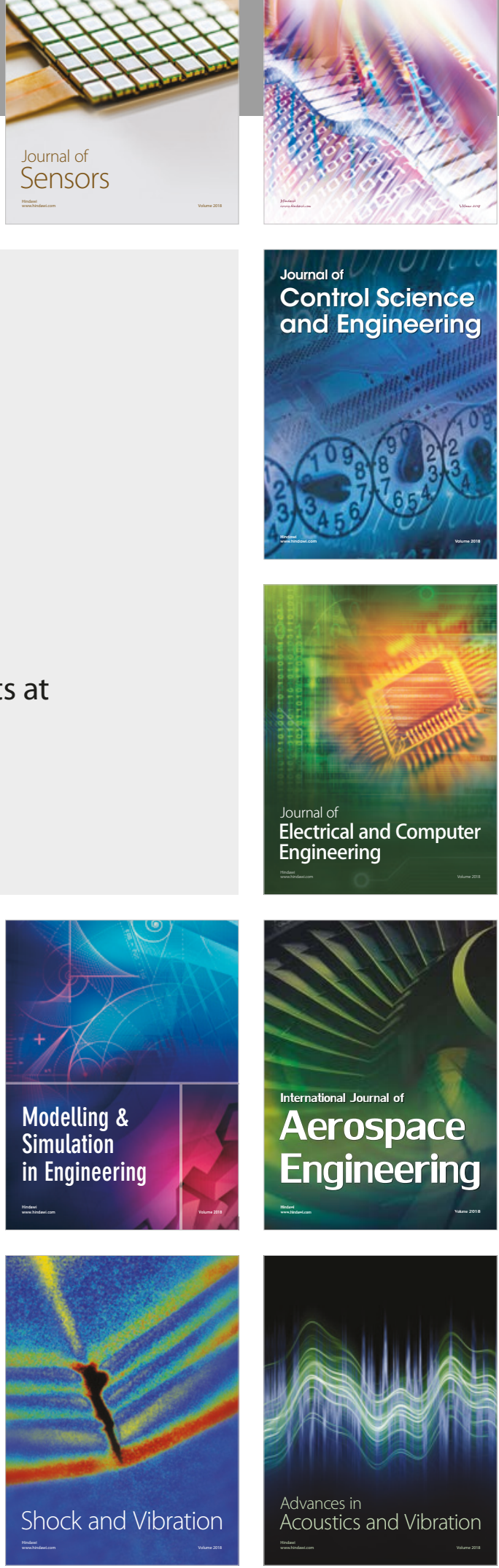